\title{
MICHEL FOUCAULT E A NOÇĀO DE PODER
}

Onde há poder, ele se exerce. Michel Foucault"

\section{Dalva Rausch"}

O presente trabalho visa apresentar como a questão do poder é tratada por Michel Foucault à partir de seu livro Vigiar e Punir e, que segundo seus críticos referem-se às suas segunda e terceira fases, resumidas a seguir. Seu próprio nome, enquanto intelectual é associado à análise da transgressão e sua teoria é permeada pela noção de crise como resultante da hostilidade radical que demonstrou em relação à ordem existente através de seus trabalhos, deixando-nos, ao falecer, em 1984, o peso de seu relativismo pessimista.

Palavras-Chave: Foucault; Poder

\section{Da Transgressão e do Poder}

$\mathrm{O}$ presente trabalho visa apresentar como a questão do poder é tratada por Michel Foucault à partir de seu livro Vigiar e Punir e, que segundo seus críticos referem-se às suas segunda e terceira fases, resumidas a seguir. Seu próprio nome, enquanto intelectual é associado à análise da transgressão e sua teoria é permeada pela noção de crise como resultante da hostilidade radical que demonstrou em relação à ordem existente através de seus trabalhos, deixando-nos, ao falecer, em 1984, o peso de seu relativismo pessimista.

Foucault admite na sociedade a existência de uma natureza incompleta subvertida através dos mecanismos de poder e de opressão (MEGILL, 1989 , p. 188-93). Pierre Bourdieu sintetizaria seu pensamento, da seguinte maneira:

uma longa exploração da transgressão, da ultrapassagem do limite social, que se liga indissoluvelmente ao conhecimento e ao poder (ÉRIBON, 1990,p. 307).

A Teoria Clássica Política e Sociológica, afirma que o poder, enquanto extensão das rédeas institucionais das classes dominantes seria responsável pela: definição oficial da realidade e, portanto suas formas de alienação; pelo tipo de exercício da coer- ção, mais flexível ou não e, entre os outros inúmeros elementos que se poderia enumerar, pelas condições ou não de sua autoperpetuação. Para Barrington Moore, o industrialismo como tipo de poder exigiria: a destinação de grandes somas de recursos humanos ou naturais; grande número de pessoas devem ser compelidas à disciplina exigida pela industrialização moderna; em cada atividade, a unidade social capaz de mobilizar ou controlar a maior soma de recursos leva uma vantagem competitiva. A compulsão está implícita no desenvolvimento de novas atividades centralizadoras ou em um sistema de coordenação centralizada (MOORE, 1972, p.: 11-21)

Ao tornar-se o valor supremo afirma Barrington Moore, o eixo do poder adquire a função principal do mito constitucional através do estabelecimento da legitimidade ou da obediência que ocorrerá sem coerção. No mundo moderno, as fontes da transformação se encontram, em parte, nas dificuldades estruturais inerentes ao industrialismo e, em parte, na erosão dos valores e crenças tradicionais, causada pelo racionalismo secular moderno. À medida que o industrialismo e o racionalismo ocidentais se espalharam para Leste, aceleraram a decadência de antigos sistemas sociais, $o$ totalitarismo centralizado moderno industrialista atrovés de um sistema descentralizado e difuso de repressão, aceito pela população em geral, representando, entretanto, um totalitarismo centralizado muitissimo mais eficiente e terrivel do que tudo

"Os Intelectuais e o Poder"- in - Microfisica do Poder

- Prof do Departamento de Ciências Sociais da Universidade Estadual de Londrina. 
o que já apareceu até agora (MOORE, 1972, p. 21-35)

Michel Foucault se interessa em saber - através do exame das práticas institucionais incorporadas sem questionamento em nossa atualidade - em que medida tais práticas exercidas internamente dentro destas instituições seriam responsáveis pela manutenção de elementos totalitários, coercitivos em nossas práticas cotidianas, hoje. Michel Foucault e Barrington Moore admitem as práticas da espionagem, da confissão, da denúncia, do terror, do controle do pensamento nas sociedades pré-industriais e na variedade moderna de totalitarismo.

Hubert L. Dreyfus e Paul Rabinow afirmam que a originalidade de Foucault reside em demonstrar exemplos de como um domínio da atividade humana deveria ser organizada. Os exemplos históricos ilustrados pelo Panóptico, pelas práticas confessionais religiosas, etc. nos mostram como nossa cultura tenta normalizar indivíduos através de meios cada vez mais racionalizados, fazendo com que os homens de seres significantes, tornem-se objetos dóceis (DREYFUS \& RABINOW, 1982. p. XII).

\section{As Noções Metodológicas e as Temáticas Recorrentes}

Foucault adirma que a representação é a episteme caraterística da Idade Clássica dos séculos XVII e XVIII, enquanto a significação é a episteme típica moderna que se inicia no final do século XVIII e que, agora, segundo ele, estaria sendo substituída pela noção de dispositivo ou aparato (MEGILL, 1989: 209). Em seus dois momentos teóricos iniciais, Foucault utilizava-se da noção episteme no sentido que Jean Piaget confere à noção de Quadro Epistêmico, entretanto, nos seus últimos trabalhos admite que a noção de dispositivo ou aparato lhe parece mais condizente para suas finalidades metodológicas (MEGILL, 1989, p. 209).

Hubert L. Dreyfus e Paul Rabinow definem a teoria de Foucault como uma analitica interpretativa por captar como os processos de mecanismos concretos de poder operam na sociedade, exemplificados através de instituições. Para os autores (DREYFUS \& RABINOW, 1982, p. 184) existiram cronologicamente três temas metodológicos nas pesquisas de Michel Foucault:

- o primeiro se refere em uma mudança da ênfase nas formações discursivas, ocorrida na metade da década de 60 , para uma abrangência maior para temas não discursivos: uma mudança para práticas culturais e poder. Esse primeiro momento de Fou- cault é freqüentemente apontado como tendo um viés estruturalista (MEGLL, 1989, p. 207-209);

- o segundo trata de seu enfoque em meticulosos rituais de poder, centrando-se em determinadas práticas culturais que combinam conhecimento e poder;

- o terceiro se refere ao isolamento da noção de "bio-poder" (FOUCAULT, 1985, p. 127) que interliga várias tecnologias do corpo, o discurso das ciências humanas e as estruturas de dominação que se articularam nos últimos 250 anos de nossa história, particularmente, desde 0 início do século XIX.

Para Michel Foucault todas as práticas através das quais o sujeito é definido e transformado são acompanhadas da formação de certos tipos de conhecimento a formação de certos tipos de saber, por sua vez, reforçaram o poder em suas malhas institucionais. Do ponto de vista metodológico, em um primeiro momento de sua trajetória intelectual, o autor coloca a Arqueologia como o método próprio de análise à discursividade local que elabora enquanto viveu na Tunísia (ÉRIBON, 1990, p. 13), o autor quer dizer:

O terreno das coisas ditas é o que se chama arquivo; a arqueologia destina-se a analisá-lo (ERIBON, 1990, p. 179).

Assim, a Genealogia seria a tática que, a partir da discursividade local ativaria os saberes libertos da sujeição que emergem desta discursividade. Por outro lado, Foucault não pretende estudar a história: a história o interessa para compreender o presente:

em suma, Foucault tentou construir um modelo de análise das práticas culturais de nossa cultura que foram instrumentalizadas na formação do individuo moderno tanto quanto objeto como sujeito (DREYFUS \& RABINOW, 1982, p. 120).

$\mathrm{Na}$ ordem de suas publicações, o autor utiliza a noção de episteme até a História da Sexualidade I: A Vontade de Saber quando começa a fazer uso da noção de dispositivo (ou aparato) definido em sua forma geral como elemento ao mesmo tempo discursivo e não-discursivo (MEGILL, 1989, p. 247). Para ele:

Temos que conhecer as condições históricas que motivam nossa conceptualização. Necessitamos ter lucidez histórica de nossa presente circunstância. (FOUCAULT apud DREYFUS \& RABINOW, 1982, p. 209).

Em Vigiar e Punir Foucault afirma que o objetivo da obra é:

uma história correlativa da alma moderna e de um novo poder de julgar; uma genealogia do 
atual complexo científico-judiciário onde o poder de punir se apoia, recebe suas justificações e suas regras, estende seus efeitos e mascara sua exorbitante singularidade (FOUCAULT, 1977 , p. 25).

Trata-se da análise de esquemas interpretativos gerados por práticas históricas específicas, isto é, o autor não se utiliza mais do termo arqueologia. Como forma de estabelecer algum nexo ou compreensão em nossa arbitrariedade, diria Paul Veyne (VEYNE, 1967, p. 297) é preciso buscar a parte imersa do icerberg dos acontecimentos perdidos na história. Procedendo desse método, reenviamos os fatos ao contexto que lhes deram sentido e assim, os conteúdos históricos específicos das palavras adquirem seu significado preciso.

Hubert L. Dreyfus e Paul Rabinow, admitem que, após escrever A História da Loucura e $\mathbf{O}$ Nascimento da Clínica, o autor - que se ativera apenas na análise do discurso - percebe que as instituições analisadas apenas do ponto de vista discursivo tornava ininteligível o poder causal atribuído às regras dos diferentes sistemas discursivos (1982, p. XX). Assim, Foucault teria abandonado a tentativa de elaborar uma teoria de sistemas governados por regras de práticas discursivas através de uma Arqueologial. Como uma técnica, a arqueologia serve a genealogia e permite fazer as seguintes questões:

Como são usados esses discursos?

Qual é o papel que eles tem na sociedade?

Em 1970, Foucault em sua Aula Inaugural no "Collège de France" afirmou que em toda sociedade a produção do discurso é ao mesmo tempo controlada, selecionada, organizada e redistribuída por determinado número de procedimentos cuja finalidade é o controle da desordem. São todos esses dispositivos de controle e domínio dos discursos sintetizam-se em sistemas de repressão que podem ser agrupados em três categorias:

\section{1. os processos de exclusão ${ }^{2}$ \\ 2. os principios de limitação ${ }^{3}$ \\ 3. as regras de efetuação}

Analisando Foucault, Paul Veyne diria que os homens e suas práticas é que devem ser o objeto do estudo histórico, não os objetos. Em outras pala-

\footnotetext{
${ }^{1}$ Arqueologia do Saber, livro publicado em 1969. Rio de Janeiro, Forense-Universitária, 1986.

2 incluem:- a proibição e o tabu; - 0 isolamento e a rejeição que re cusam: a palavra do louco;- a vontade da verdade como máquina de exclusão.

3 servindo-se de:- o comentário que duplica o texto; - a noção de autor e sua estranha singularidade; - as disciplinas cientificas e outras que classificam o saber maginalizando o que não conseguem assimilar.

impostas ao discurso:- rituais de seu uso na sociedade; - exigências prévias antes de ter o direito e a condição de falar. Didier Éribon, 1990, pps.202-204.
}

vras, é preciso desviar nossos olhos reificados dos objetos naturais porque esquecemos a prática e tendemos a ver somente objetos reificados em nossa volta. É necessário, portanto, percorrer o caminho inverso (VEYNE, 1967, p. 207-8). Quer dizer, existem práticas diferentes que objetivam que objetivam as convenções e o vocabulário usado pelas pessoas que vivem em um determinado momento histórico, existem pressupostos na linguagem que são residuais e típicos de cada época. Enfim, os homens apenas virtualizam as práticas possíveis existentes em seu campo histórico durante sua curta existência.

Dessa maneira, é preciso julgar as pessoas pelo seus atos e não pelas suas ideologias ou noções eternas que lhes imputamos. Assim, podemos perceber que as noções pelas quais as pessoas se tratam são relacionais: são objetivações, correlatos de uma certa prática política.

\section{Assim, os objetos parecem determinar nossa conduta, mas nossa prática é quem determinou esses objetos. Partamos, portanto, dessa práti- ca mesma de tal maneira que o objeto à qual ela se aplica seja somente em relação à essa prática: a relação determina o objeto e existem apenas objetos determinados (veyne, 1967, p.} 212).

A importância da análise de Foucault na questão do poder, em primeiro lugar, refere-se ao fato dele ter isolado e identificado a maneira como nossa sociedade é organizadamente permeada pelo poder-bio-técnico cuja meta, segundo Hubert L. Dreyfus e Paul Rabinow é o aumento da ordem e do poder na sociedade. Em segundo lugar, sua contribuição metodológica é inédita no tocante à ênfase que ele dá ao corpo humano como o lugar através do qual as práticas sociais estão interligadas dentro de uma escala mais ampla de organização de poder (DREYFUS \& RABINOW, 1982, p. XII; FOUCAULT, 1985, p. 92). Em "Nietzche, a Genealogia e a História", Foucault define o corpo como a superficie de inscrição de acontecimentos, o lugar de dissociação do Eu, um volume em perpétua pulverização. A genealogia, dessa maneira, como análise da proveniência estaria, portanto, no ponto de articulação do corpo com a história. Ela deve mostrar o corpo inteiramente marcado de história $e$ a história arruinando o corpo (FOUCAULT, 1986, p. 22).

Em 1975, Foucault diria em Vigiar e Punir:

...mas o corpo também está diretamente mergulhado num campo político; as relações de poder têm alcance imediato sobre ele: elas o investem o marcam, o dirigem, o supliciam...Este investimento politico do corpo está ligado... à sua utilização econômica ... enquanto força de 
produção o corpo é investido por relações de poder e de dominação $(1977$, p. 28).

\section{A microfísica do poder: a rede, o corpo, os saberes:}

Para Ian Burkitt (1933, p. 34) em Michel Foucault a noção de poder designa relacionamento entre parceiros: o poder deve ser pensado mais como uma relação do que como uma coisa. A relação de poder engendra um certo tipo de relacionamento que é assim definido, retomando as palavras do próprio Foucault:

ela é, entretanto, sempre uma maneira de agir sobre um sujeito atuante ou sobre vários sujeitos atuantes em virtude de suas ações ou por ser apto a agir. Em suma, um conjunto de ações sobre outras ações (FOUCAULT apud BURKITT, 1933, p. 55).

A partir de Vigiar e Punir, Foucault admite que duas idéias são interligadas ao poder:

- o poder é produtivo bem como o poder é restriti$v o$;

- o poder se refere ações dentro de relacionamentos.

A palavra produtivo, entretanto, referente ao poder deve ser interpretrada no sentido de que o poder produz, produz realidades, isto é: o papel da prisão não é reprimir a delinqüência, mas criá-la! (MEGLL, 1989, p. 241) Assim, o autor interpreta o poder como uma questão de grau. Vale dizer, ninguém tem absoluta autonomia em uma relação de poder bem como ninguém é absolutamente determinado pelo mesmo. O autor rejeita situações de determinismos político-econômicos e de legitimidade no exercício da violência física, tal como a escravatura, para exemplificar uma situação de poder. Assim, relações de poder apenas podem ocorrer e ser definidas em face a oposições e tal fato ocorre somente quando as pessoas são fisicamente capazes de fazer escolhas livres.

Em A Vontade de Saber, o autor liberta-se da idéia de que o poder é mau, estéril e monótono. Se o problema é o poder, afirma Michel Foucault, dispomos de poucos instrumentos além daqueles oferecidos pela análise econômica. Para o autor:

o poder não se dá, não se troca nem se retoma, mas se exerce, o que é exercido e tal exercicio é essencialmente de natureza repressiva. $O$ problema, é que no interior de uma pseudo-paz civil contratual, a repressão seria a prática de uma relação perpétua de força. (1986, p. 175177)
Assim, a questão do poder não é uma questão teórica, mas empírica, envolvendo a observação e análise de instâncias específicas onde as relações de poder foram colocadas em operação. Analisando - que seja uma relação ao poder, interessaria saber não o por que, mas como ele é exercido. Em outros termos, como o poder é aplicado, por quem e sobre quem?

Analisando instituições específicas, Foucault buscou o exercício do poder dentro delas e a metodologia aplicada por ele se denominaria microfisica do poder ${ }^{5}$. Foucault rechaça todos os ismos e todas as noções tidas como eternas - em uma clara crítica a Karl Marx e a Sigmund Freud - como chaves que abrem todas as portas e cobrem com um manto a originalidade e a diferenciação das práticas humanas. A questão do estabelecimento de uma determinada ordem na sociedade deveria ser abordada observando as técnicas através das quais tal ordem é atingida do que teorizar sobre como tal ordem poder jamais ser possível. (BURKITT, 1993, p. 57).

A análise que faz de instituições se deve ao fator heurístico explicativo das práticas e da inteligibilidade social que as elegem ou as criam em um determinado momento histórico e que nos auxiliam a interpretar nosso presente. As microfisicas de poder inseridas na realidade são percebidas através dos efeitos por elas induzidos em toda a rede em que se encontram. Por exemplo, a construção do Panóptico de Bentham, na tematização foucaultiana é em si mesma neutra. Apenas quando tal construção se investe para estabelecer o controle dos corpos e dos espaços para exercer o poder ela se torna fundamental e tipológica.

O Panóptico permite a eficiência do exercício do poder, aumenta ao máximo a visibilidade das pessoas visadas e envolve, em seu funcionamento, todos os que entram em seu aparato: soma a conexão entre corpos, espaços, poder e conhecimento. Usando as palavras de Hubert L. Dreyfus e Paul Rabinow:

\section{A teoria de Foucault aponta que a tendência do poder em se despersonalizar, ser difuso, relacional e anônimo e ao mesmo tempo, tota- lizando cada vez mais maiores dimensões da vida social e não apenas na posse do mesmo (1982, p. 192).}

Sua concepção de poder admite que ele seja uma rede de relações que envolve um certo tipo de saber, isto é, o saber investido nos sistemas complexos de instituições tais como: fábricas, escolas, hospitais, Hospitais Psiquiátricos, Penitenciárias, etc. e que exercem como uma prática cotidiana e regulamentada por todos. Se o corpo é o lugar onde tal poder é exercido, diria o autor:

\footnotetext{
${ }^{5}$ Michel Foucault, Vigiar e Punir e Microfísica do Poder.
} 
esse saber e esse controle constituem o que se poderia chamar de tecnologia politica do corpo que nada mais é do que uma microfísica do poder posta em jogo pelos aparelhos e instituições (FOUCAULT, 1977, p. 29)..

Segundo Alan Megill o que está sendo considerado são os mecanismos de ordem e de exclusão sociais existentes desde o século XVI e, principalmente, aqueles referentes à Europa no final do século XVIII. Foucault, entretanto, centraliza sua análise não nos mecanismos de opressão e de exclusão mas, nas maneiras de pensar e de falar que a ordem dominante cria para si mesma $(1989, \mathrm{p}$. 192).

O desenvolvimento desse saber e suas transformações põem em jogo relações complexas de causalidade. Aqui, a noção de saber como um domínio particular situa-se entre a opinião e o conhecimento cientifico (ÉRIBON, 1982, p. 200). Tal saber visaria tornar eficiente, científico e bem-sucedido o exercício do poder nas instituições através de tecnologias disciplinares do corpo mascarada de neutralidade e padronização. $O$ poder mesclado nos diferentes saberes faz que 0 autor afirme sua recusa em formular um discurso de verdade sobre uma ciência qualquer na medida e que "legislar para toda a ciência é o projeto positivista" (FOUCAULT, 1986, p. 154). Acusa o desenvolvimento das Humanidades a serviço do positivismo ligado às instituições de reclusão, objeto de sua análise.

A proliferação de instituições que se iniciaram nos séculos XVI e XVII aos nossos dias permitiu que tal saber se reproduzisse em disciplinas. O novo sistema penitenciário surgiu no início do século XIX e serviu, entre outras coisas, como um laboratório para a constituição de um corpo de conhecimentos sobre os criminosos e seus crimes com intenção normativa. Isso não significa, entretanto, que o sistema penitenciário tenha sido bem sucedido. As prisões jamais apresentaram senão sucessos parciais. A questão de sua manutenção dentro das práticas sociais passa a responder muito mais pelo fato de haver isolado anomalias e as ter normatizado, tratado ou reformado através da linguagem neutra da ciência (DREYFUS \& RABINOW, 1982, p. 194-197).

Michel Foucault aponta, então, o caráter local da crítica e que ela, como segunda caraterística, se efetivaria pelo retorno do saber. Saber, aqui, tido como uma espécie de produção teórica autônoma, não centralizada, isto é, que não tem necessidade, para estabelecer sua validade, da concordância de um sistema comum (DREYFUS \& RABINOW, 1982, p. 169).

O autor confessa que os fragmentos de genealogias que elaborou em anos de pesquisas permanecem cercados por um silêncio prudente. Pelo mesmo motivo, afirma Paul Veyne, a história não é a Utopia. Isto é, as políticas não se desenvolvem através de grandes princípios, elas são criações históricas e não criações da Consciência ou da Razão. Assim, a ideologia é bem livre e ampla e por um motivo: ela é a racionalização, a idealização, é um grande manto (VEYNE, 1967, p. 215). Nem por isso, entretanto, Foucault despreza o aparato de poder cercando os campos de saber e do perigo de tal narcissismo intelectual. Na verdade, 0 autor reflete sobre a ambição de poder que a pretensão de ser uma ciência traz consigo, perguntando:

que tipo de saber vocês querem desqualificar no momento em que vocês dizem [isto] "é uma ciência"? (FOUCAULT, 1986, p. 172)

Da mesma maneira, o estabelecimento das relações de poder não podem ser separadas das técnicas e estratégias empregadas pelos indivíduos e grupos em combate uns com os outros. A dificuldade da adoção desse método, que o autor denomina de Genealogia, consiste em abandonar as Grandes Teorias ou os Grandes Gigantes dos diferentes campos explicativos científicos nas humanidades, tais como Karl Marx e Sigmund Freud.

Para Foucault devemos admitir que nosso conhecimento é em grande extensão preconceitural, uma anti-ciência. No entanto, se arrancamos o manto das noções eternas perceberemos que há muito mais a ser explicado e que estava abaixo da linha da visibilidade, reafirmando o efeito de refreamento das teorias totais. Os fatos humanos são arbitrários. Ou ainda, a genealogia se opõe ao desdobramento meta-histórico das significações ideais e das indefinidas teleologias. Ela se opõe à pesquisa da origem.

A Genealogia só seria possível se fosse eliminada a tirania dos discursos englobantes com suas hierarquias e com os privilégios da vanguarda teórica. Como diria o autor na Genealogia o que lhe reprovamos é fazer do marxismo, da psicanálise ou de qualquer outra coisa, uma ciência. Assim como a genealogia critica as grandes teorias ela também é a recusa da busca da origem. Em suas palavras:

A história ensina também a rir das solenidades da origem...gosta-se de acreditar que as coisas em seu inicio se encontravam em estado de perfeição. (FOUCAULT, 1986, p. 16-18)

Assim, os termos históricos que designam gladiadores, governantes, governados adquirem uma significação histórica diferente fora de seus limites perceptíveis. Foucault critica as noções eternas tais como: governados, governantes, Senado, Estado, a essência da política "que banalizam e tornam anacrônicas a originalidade das práticas sucessivas". Para 0 autor as noções eternas são chaves que abrem todas as portas, mas não abrem a compreen- 
são dos acontecimentos particulares. Em outras palavras, para ele as palavras nos abusam: elas nos fazem crer na existência das coisas, em objetos naturais enquanto que, repetindo, as coisas são apenas correlatos de práticas correspondentes. Isto ocorre porque a semântica é a encarnação da ilusão idealista.

Analisando discursos considerados desqualificados, critica as teorias globalizantes, mencionando críticas descontínuas, particulares e locais ao saber instituído, Foucault (MEGILL, 1989, p. 195) assinala uma preocupação na recuperação dos saberes locais, dos saberes ingênuos, dos saberes desqualificados e a constatação da existência das críticas descontínuas permitiria afirmar que um processo de desmascaramento estivesse ocorrendo. Os saberes locais, os saberes dominados seriam definidos do seguinte modo pelo autor:

uma série de saberes que tinha sido desqualificados como não competentes ou insuficientemente elaborados; saberes ingênuos, hierarquicamente inferiores, saberes abaixo do nivel requerido de conhecimento ou de cientificidade. (FOUCAULT, 1986, p. 169-70)

Existe sobre o discurso consciente uma gramática determinada pelas práticas e pelas gramáticas vizinhas. Percebe-se, então que o discurso não é nem semântica, nem ideologia, nem aquilo que é implícito. Enfim, o discurso ou sua gramática escondida não é o implícito: ele não constitui uma axiomática ou um pressuposto geral pelo simples fato de que aquilo que é dito ou feito pertence à dimensão de uma gramática do acaso, mostrando os azares da história, as saliências e reentrâncias das práticas vizinhas e as transformações de sua época e não à uma gramática lógica, coerente, perfeita, obra da Razão edificando um sistema coerente.

Os saberes dominados seriam:

a) conteúdos históricos que foram sepultados, mascarados em coerências funcionais ou em sistematizações formais;

b) uma série de saberes que tinham sido desqualificados como não competentes ou insuficientemente elaborados: saberes ingênuos, hierarquicamente inferiores, saberes abaixo do nivel requerido de conhecimento ou de cientificidade.

Em 1976, fazendo uma sintese de suas pesquisas nos dez anos que haviam precedido, Michel Foucault afirmou que resultante das mesmas havia percebido nos fatos algo inesperado - ao lado das criticas descontinuas, particulares e locais, aquilo que se poderia chamar de efeito inibidor próprio às teorias totalitárias, globais $(1986$, p. 169).

Por outro lado, esses saberes locais que, segundo o autor, estariam aparecendo como crítica, constituiriam um saber diferencial incapaz de unanimidade cuja força se deve à oposição a todos aqueles saberes que o circundam. Antes disso, em 1986, o autor já havia afirmado que a emergência é a entrada em cena das forças enquanto a proveniência designa a qualidade de um instinto. Se a emergência surpreende é porque ela se produz no interstício, ninguém é responsável por ela...ela sempre se produz no interstício. Para Michel Foucault foi justamente o acoplamento entre o saber sem vida da erudição $e$ o saber desqualificado pela hierarquia dos conhecimentos e das ciências que deu à crítica destes últimos anos sua força essencial. Para ambos os tipos de saber: o da erudição e o desqualificado, nestas duas formas de saber sepultado ou dominado, se tratava na realidade do saber histórico da luta (1986, p. 170).

Respondendo ao trabalho de Hubert L. Dreyfus e Paul Rabinow, no início da década de 80, afirmou que o tema geral de sua pesquisa não é o poder, mas sim o sujeito. Para Foucault, existem dois tipos de sujeitos:

- sujeito para alguém através de controle e dependência; $e$

- sujeito ligado à sua própria identidade pela consciência ou conhecimento de si mesmo. (1986, p. 212)

Os dois significados de sujeito acima sugerem uma forma de poder que o subjugam e o tornam sujeito de algo ou de alguém. Acusa ainda o excesso de racionalismo de nossa época e as relações com o poder. Assim, elaborando a datação das diferentes técnicas de repressão da sexualidade, o autor afirma que a fixação do dispositivo de sexualidade sobre o sistema da aliança visava sobretudo a burguesia preocupada na saúde do corpo e na sua manutenção e transmissão de sua hegememonia política-econômica a seus herdeiros.

Foucault admite a existência da prática da Confissã $o^{6}$ como um mecanismo de poder de coerção individual judaico-cristão que tem na Reforma, - Consistório sua contrapartida. As duas práticas exemplificam o tolitarismo centralizador préindustrial. ${ }^{7} \mathrm{O}$ resultado das diferentes práticas coercitivas, no entanto, não nos deve iludir, segundo o autor afirma em 1977:

Mas não devemos nos enganar: a alma, ilusão dos teólogos, não foi substituída por um homem real, objeto de saber, de reflexão filosófica ou

\footnotetext{
${ }^{6}$ Michel Foucault, 1985, pps.58 e seguintes.

7 analisando o calvinismo suiço em 1558, afirma que o Consistório conce bido apenas como dispositivo para supervisionar as questões conjugais, veio a ser o principal centro de controle políti$\mathrm{co}$, moral e religioso. O Consistório exercia as funções de polícia secreta e censor moral: nada escapava ao co nhecimento do Consistório. Após reprimir todos os rituais católicos ainda re miniscentes, em 1546 uma lei proibiu os passatempos favoritos em Genebra tais como: festas, danças, dados etc.; O Consistório definia ainda o feio das rou pas, sapato dos habitantes e dieta alimentar. Barrington Moore, 1972, p.67.
} 
de intervenção técnica. O homem de que nos falam e que nos convidam a liberar já é em si mesmo o efeito de uma sujeição bem mais profunda que ele. Uma "alma" o habita e o leva à existência, que é ela mesma uma peça no dominio exercido pelo poder sobre o corpo. A alma, efeito e instrumento de uma anatomia politica; a alma, prisão do corpo.

(FOUCAULT, 1977, p. 31-32)

\section{Conclusão: da sujeição à derelição}

A recusa à submissão de uma relação de poder é definida por Michel Foucault como agonismo, cuja origem advém de F. Nietzsche. Para o autor a relacão de poder e a recusa de uma pessoa livre em submeter-se à ela não podem ser interpretadas isoladamente. Para ele a noção de poder e de liberdade não são dois opostos, mas integrantes uma da outra (BURKITT, 1993, p. 55-56; MEGILL, 1989 , p. 188).

Nessa linha, o conceito de agonismo sugere um combate permanente entre indivíduos e grupos onde existe a constante possibilidade de liberdade de ação e também onde existe a précondição da emergência de relações de poder. $\mathrm{Na}$ verdade, trata-se de desreificar os próprios conceitos de poder e de liberdade. Para Allan Megill a maneira como Foucault utiliza a noção de poder ou vontade de poder além de denunciar as raízes nietzschianas do conceito, demonstram a associação feita com a noção de presente como derelição, de Martin Heidegger.

Martin Heidegger define a derelição como a experiência que tem o homem ( $o$ Dasein) enquanto ser jogado e abandonado nas vicissitudes de uma existência que the foi imposta $(1964$, p. 215$)$. Tal como no "Mito de Sísifo" de Albert Camus, existe, nessa definição a idéia de que a derelição enquanto abandono é própria da condição humana. Assim, tanto para Heidegger quanto para Foucault nosso presente é derelito em caráter (MEGLL, 1989, p. 194). Em suas palavras:

Analisar o investimento politico do corpo e a microfisica do poder supõe então que se renuncie - no que se refere ao poder - à oposição violência-ideologia, à metáfora da propriedade, ao modelo do contrato ou ao da conquista (FOUCAULT, 1977, p. 30).

Se a opção que Martin Heidegger assume quando denuncia o caráter de derelição do presente é de passividade na medida em que qualquer ação que pudesse tomar se tornaria parte da degradação presente. Foucault, por sua vez, escolhe, através de seu discurso, de sua fala radical ativista tomar uma iniciativa sem fim que vise acabar com todas as ordens passadas, presentes e futuras.

Em lugar de teorizá-las como duas forças opostas com energia própria e uma capacidade para oprimir ou liberar, agora poder e liberdade devem ser vistos como elementos permanentes contidos dentro de relações entre combatentes. Poder e liberdade não são forças mas aspectos das relações sociais de contestação. Ambas devem sempre ser analisadas como relações e não como coisas. Em "Nietzsche, a Genealogia e a História", Foucault afirma que a razão nasceu do acaso de uma maneira inteiramente desrazoável.

Ironicamente, a seguir, pergunta: $E$ a liberdade? seria ela na raiz do homem o que o liga ao ser e à verdade? - o que ela deveria ser - De fato, continua ele, ela é apenas uma invenção das classes dominantes (1986, p. 18).

Ian Berkitt afirma então que nesse momento se coloca a questão da realidade do poder. Para Berkitt, em Foucault o poder somente existe onde emergem relações de conflito entre grupos e indivíduos. Ao que Barrington Moore acrescentaria que na modernidade existe uma tirania da maioria cujo traço mais notável seria a mudança na definição e nas dimensões da autonomia e da liberdade humanas (1972, p. 76).

Ian Burkitt, em sua interpreção de Foucault, afirma que existe de um lado, a tentativa de estabelecer padrões bem-direcionados e estáveis de conduta dentro das relações antagônicas puras, enquanto que, de outro lado, existe uma estratégia de luta que cria resistências e um limite a qualquer sucesso possivel na arte de governar (1993, p. 57). Para os comentadores de Foucault, leitores de Filosofia, sua dívida a F. Nietzsche novamente se confirma quando o autor, criticando nossa civilização como apolínea, derivativa dos conceitos socráticos e de Platão, contra o culto a Dionísio que ele quer restaurar como já o tentara F. Nietzsche em Assim Falava Zaratustra.

Segundo Barrington Moore, a principal diferença entre as doutrinas pré-industriais e as doutrinas modernas prende-se ao estádio histórico alcançado pela noção de razão. Se nas doutrinas préindustriais a noção de razão - definida por Michel Foucault como Idade Clássica da representação nas doutrinas modernas a razão, para Barrington Moore foi degradada à condição de instrumento técnico de escolha entre métodos, e, privada, ao mesmo tempo do poder de apreciar os fins. $O$ autor - repetindo as teses de Foucault - conclui, nessa linha, afirmando que os controles do totalitarismo moderno se aprofundam muito mais na estrutura social do que em qualquer outro exemplo da História (MOORE, 1972, p. 70-71).

Se adotamos a análise do discurso - na sua primeira fase - como objeto de aplicação de seu méto- 
do: a palavra discurso adquire o sentido daquilo que é dito assim como a palavra prática designa o que é praticado. Assim, não mais o saber, mas a vida, não mais o conhecimento, mas o real. Ocorre, entretanto, que a dimensão do que é dito encobre tomadas de posições, reticências, inesperadas saliências e reentrâncias sobre os quais os locutores não estão absolutamente conscientes, isto é, quando falo, esqueço as regras gramaticais que governam minha língua (VEYNE, 1967, p. 211-214). Segundo Paul Veyne, o que interessa a Michel Foucault, Não é a estrutura, o corte ou o discurso: mas a "raridade".

Allan Megill afirma que para Foucault, a história se torna efetiva quando introduz a descontinuidade em nosso próprio ser, quando ela nos tira da estabilidade de sermos nós mesmos, de estarmos vivos e de nossa natureza. Tal história é de cunho paródico, é dissociativa, direcionada contra identidade...ela é sacrificial, dirigida contra a verdade.

No tocante à função sacrificial, Foucault insiste particularmente na noção de poder do conhecimento que arbitrariamente estabelece sua própria verdade. Tal verdade é violenta e coercitiva em caráter, gerando uma progressiva escravidão em sua violência instintiva (MEGLL, 1989, p. 236). A conseqüência para Michel Foucault seria reduzir nossa história a um processo intelectual tão implacável quanto irresponsável, em suas palavras:

A paixão do conhecimento talvez até mate a humanidade. Se a paixão do conhecimento não matar a humanidade ela morrerá de fraqueza. Queremos que a humanidade se acabe no fogo e na luz, ou na areia? (FOUCAULT, 1989, p. 36)

O caráter agonístico do projeto de Foucault está, aqui, completamente descoberto. Não importa, enquanto um pensador da crise, o autor está implicitamente engajado com a noção de que a ordem reinante, não importa sua natureza, é decadente (MEGLL, 1989, p. 239). À tal insistência Hubert L. Dreyfus e Paul Rabinow interpretam que para Foucault nos demonstra a existência de duas dimensões estratégicas de práticas totalizadoras em curso que não somente produzem o homem como objetos, mas, principalmente, preservam ambos, homem e objetos, em nossa sociedade, aqui acusada de ser obcecada por sentido. É justamente este diagnóstico que permite a Foucault definir nossa atual situação cultural (DREYFUS \& RABINOW, 1982, p. XXI). Trata-se de perguntar: quem somos nós?

respondê-la significaria, entretanto, escapar aos efeitos dos quais somos reflexos em nossa condição de imersão histórica. Ao mesmo tempo, seria ingênuo de pensar que os sistemas disciplinares de microfísicas de poder ocorrem apenas em sistemas de reclusão. Tais sistemas (disciplinares) existem através toda a sociedade burguesa e controlam nosso comportamento com ou sem nosso conhecimento disso. Todo exercício disciplinar dentro da sociedade moderna pressupõe um mecanismo que exerce o poder de coerção através do olhar (MEGILL, 1989, p. 242).

Saber, mesmo na ordem histórica, não significa 'reencontrar' e sobretudo não significa 'reencontrar-nos'. A história será efetiva na medida em que ela reintroduzir o descontínuo em nosso próprio ser....as forças que se encontram em jogo na história não obedecem nem a uma autodestinação, nem a uma mecânica, mas ao acaso da luta (FOUCAULT, 1986:27).

No primeiro Volume da História da Serualidade Foucault anuncia que visa estudar uma analítica do poder que definiria os domínios específicos formados pelas relações de poder. Entretanto, a reflexão sobre a questão do poder feita por Foucault relaciona-se com a noção nietzcheana de vontade de poder. Combatendo a historiografia corrente bem como a célebre noção de telos ou finalidade, afirmou:

\section{Cremos que nosso presente se apoia em inten- ções profundas, necessidades estáveis; exigi- mos dos historiadores que nos convençam dis- so. Mas, o verdadeiro sentido histórico reco- nhece que nós vivemos sem referências ou sem coordenadas originárias, em miríades de acontecimentos perdidos (FOUCAULT, 1986, p. 29).}

O autor pretende libertar a história do modelo, ao mesmo tempo metafísico e antropológico da memória...as religiões de outrora exigiam o sacrificio do corpo humano; o saber conclama hoje as experiências sobre nós mesmos, ao sacrificio do sujeito do conhecimento. Talvez que a vontade de verdade seja limitada pela finitude do conhecimento! Mas que ela perde todo o limite e toda a intenção de verdade no sacrificio que deve fazer do sujeito de conhecimento. Assim, a crítica das injustiças do passado pela verdade que 0 homem detém hoje torna-se destruição do sujeito de conhecimento pela injustiça própria da vontade de saber. Repetindo Friedrich Nietzsche, o autor diria:

não se trata mais de julgar nosso passado em nome de uma verdade que o nosso presente seria o único a deter. Trata-se de arriscar a destruição do sujeito de conhecimento na vontade, indefinidamente desdobrada, de saber

(FOUCAULT, 1986:37). 


\section{Referências Bibliográficas}

BURKITT, I., "Overcoming Metaphysics: Elias and Foucault on Power and Freedom" Philosophy of the Social Sciences, v. 23, n. 1, 1993.

DREYFUS, H. L., RABINOW, P. Michel Foucault: Beyond Structuralism and Hermeneutics. Chicago: The University of Chicago Press, 1982

ÉRIBON, D. Michel Foucault: 1926-1984. São

Paulo: Cia. de Letras, 1990.

FOUCAULT, M. A Arqueologia do Saber. Rio de Janeiro: Forense-Universitária, 1986. "Afterword: The Subject and Power".

In: DREYFUS, H. L., RABINOW, P. Michel Foucault: Beyond Structuralism and Hermeneutics. Chicago: The University of Chicago Press, 1982.

História da Sexualidade I: A Vontade de Saber, Rio de Janeiro, Graal, 1985.
"Nietzsche, a Genealogia e a História"

In: Microfísica do Poder -, Rio de Janeiro, Graal, 1986.

"Genealogia e Poder" In: Microfísica

do Poder. Rio de Janeiro: Graal, 1986. , "Os Intelectuais e o Poder" In: Microfísica do Poder. Rio de Janeiro: Graal, 1986. 1977.

HEIDEGGER, M., L'Être et le Temps. Paris: Gallimard, 1964

PIAGET, J., Psychogenèse et Histoire des Sciences. Paris: Flammarion/Bibliothèque Scientifique, 1983.

MEGILL, A., Prophets of Extremity: Nietzsche, Heidegger, Foucault, Derrida. Los Angeles: Univ. of Berkeley California Press, 1989.

MOORE, B., "Notas sobre o Processo de Aquisição do Poder". In: Poder Político e Teoria Social, São Paulo, Cultrix, 1972.

VEYNE, P., Foucault révolutionne l'histoire. Paris: Gallimard, 1977. 